\title{
Effects of Minor Additions of Polypyrrole on the Thermal, Mechanical and Electrochemical Properties of Epoxy-2Pack Coatings
}

\author{
Mohammad Asif Alam ${ }^{1}$, Ubair Abdus Samad ${ }^{1,2}$, El-Sayed M. Sherif ${ }^{1,3, *}$, Othman Alothman ${ }^{2}$, \\ Asiful H. Seikh ${ }^{1}$ and Saeed M. Al-Zahrani ${ }^{1,2,4}$ \\ ${ }^{1}$ Center of Excellence for Research in Engineering Materials (CEREM), Advanced Manufacturing \\ Institute (AMI), King Saud University, P. O. Box 800, Al-Riyadh 11421, Saudi Arabia \\ ${ }^{2}$ Chemical Engineering Department, College of Engineering, King Saud University, P.O. Box 800, Al- \\ Riyadh 11421, Saudi Arabia \\ ${ }^{3}$ Electrochemistry and Corrosion Laboratory, Department of Physical Chemistry, National Research \\ Centre (NRC), Dokki, 12622 Cairo, Egypt \\ ${ }^{4}$ SABIC Polymer Research Center (SPRC), Department of Chemical Engineering, College of \\ Engineering, King Saud University, P.O. Box 800, Al-Riyadh 11421, Saudi Arabia \\ *E-mail: esherif@ksu.edu.sa
}

doi: $10.20964 / 2017.01 .01$

Received: 26 September 2016 / Accepted: 21 October 2016 / Published: 12 December 2016

In this study, polypyrrole (PPy) conductive polymer was incorporated and dispersed in epoxy coating formulations using a sonication process. Mechanical properties of the prepared coating formulations obtained by the addition of $0.16,0.25,0.64$, and $0.95 \mathrm{wt} . \%$ of PPy were evaluated by the conventional mechanical testing following ASTM standards and nanoindentation technique. The anticorrosive properties of the steel coated samples were investigated by exposing to $3.5 \% \mathrm{NaCl}$ solution for different periods of exposure varied from 1.0 hour to 21 days. The resistance against corrosion was measured by electrochemical impedance spectroscopy (EIS), while the functional group identification was done by FTIR-ATR analysis. The morphology of the surface for the different epoxy coatings was investigated by field emission scanning electron microscopy (FE-SEM). Results revealed that coatings possessed superior anticorrosion properties with increasing percentages of PPy as indicated by EIS data as well as improved the mechanical properties as confirmed by the nanoindentation measurements.

Keywords: protective coatings; polypyrrole; nanoindentation; hardness; corrosion; EIS FULL TEXT 
(C) 2017 The Authors. Published by ESG (www.electrochemsci.org). This article is an open access article distributed under the terms and conditions of the Creative Commons Attribution license (http://creativecommons.org/licenses/by/4.0/). 